\title{
CORRECTION
}

View Article Online

View Journal I View Issue

\section{Correction: Removal of dyes by a novel fly ash- chitosan-graphene oxide composite adsorbent}

Cite this: RSC Adv., 2016, 6, 26885

Guanghong Sheng, ${ }^{\text {*ab }}$ Shuang Zhu, ${ }^{a}$ Shisheng Wang ${ }^{a}$ and Zhiyu Wang ${ }^{a}$

DOI: 10.1039/c6ra90023b

www.rsc.org/advances

Correction for 'Removal of dyes by a novel fly ash-chitosan-graphene oxide composite adsorbent' by Guanghong Sheng et al., RSC Adv., 2016, 6, 17987-17994.

The authors regret that an incorrect chemical structure for chitosan was depicted in Scheme 1 of the original article. The amended version of this image is shown below.

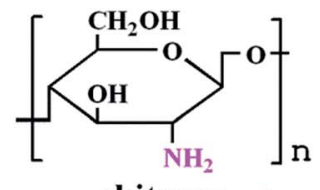

chitosan

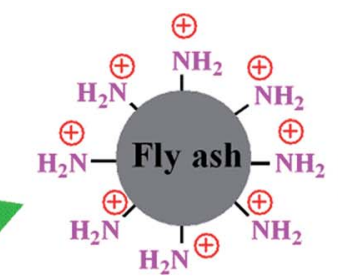

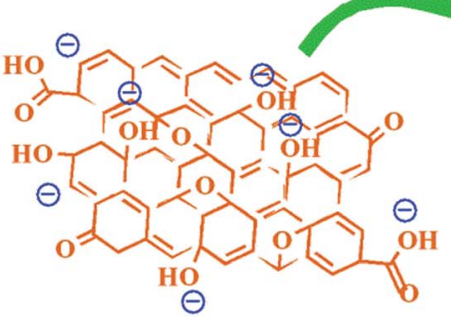

GO

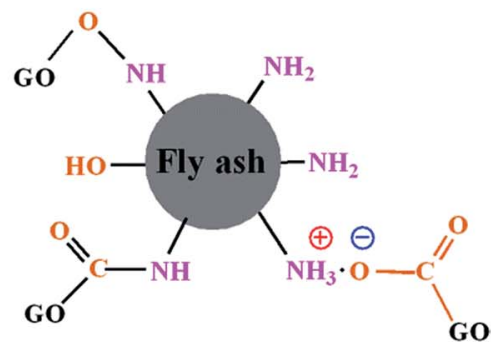

FCGO

Scheme 1 Preparation process of FCGO adsorbent.

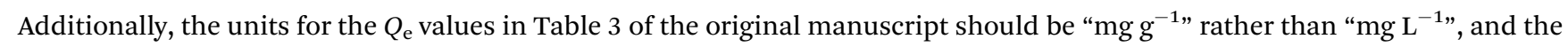
units for $\Delta S^{0}$ in the Conclusions should be " $\mathrm{J} \mathrm{mol}^{-1} \mathrm{~K}^{-1}$ " rather than "J $\mathrm{mol} \mathrm{K}{ }^{-1}$ ".

The Royal Society of Chemistry apologises for these errors and any consequent inconvenience to authors and readers. 